\title{
IMPORTÂNCIA DO DIREITO ADMINISTRATIVO COMPARADO
}

\author{
MAURO ROBERTO GOMES DE MATTOS
}

1. Direito Administrativo Comparado - 2. Estudo Comparado do Direito Público e sua Aplicação no Direito Interno - 3. Direito Comparado como Método de Estudo - 4. Conclusão.

\section{Direito administrativo comparado}

"La comparación es un simple instrumento de la comprensión. No hay efectivo conocimiento que no sea coparativo. Pero no hay efectiva comparación que no sea comprensiva. En un reciente diccionario de sinónimos, la palabra comprender se caracteriza por ser una de las más generosamente dotadas de voces gemelas en lengua castellana. El derecho que no comprende, ni sabe ni aprende. Comprender, decía el poeta, es, en último término, advertir lo bello de lo vulgar, y no lo vulgar de lo bello". (Eduardo J. Couture, discurso de apertura como decano de la Facultad de Derecho y Ciencias Sociales de la Universidad de Montevideo en "Jornadas de Derecho Comparado". Septiembre-octubre 1954". Publicación del Centro de Estudios de Derecho Comparado, Montevideo, 1955, p. 38).

O direito administrativo, como ramo autônomo, nasceu no início do Século XIX, fruto das Revoluções, importando e incorporando princípios constitucionais como marco de atuação deste novo direito. Não resta dúvida nenhuma de que através dos princípios revolucionários os países que marcharam sobre o manto do direito e da democracia importaram estas idéias para o direito interno de suas nações, criando sociedades livres e justas, contra a opressão até então reinante, onde o mais forte era o verdugo do abastado.

Assim, pela necessidade de harmonização jurídica que é objetivo comunitário, a corporação de direitos "é um rasgar de de horizontes, o abrir de janelas sobre o 
mundo, num mundo que o jurista positivista, esclerosado e estatalista (xenófobo, também) julgava acabar na última página do seu Código Nacional"'.

No presente caso, como o direito administrativo se desenvolveu tardiamente ${ }^{2}$, através de numerosos estudos despontados no início do Século $\mathrm{XX}$, onde se pode citar com precisão as laboriosas contribuições de Mayer, Jéze Laferriére, Dicey, Zanobini, Hauriou e muitos outros, houve a necessidade de se importar as diversas teorias nascidas, que serviriam de esteio para o cenário nacional de cada país. Coube assim, a comparação de princípios constitucionais que desaguaram na "Carta das Liberdades", influenciando diretamente o direito administrativo, que aceitou a idéia de que a irresponsabilidade do Estado era coisa do passado, não podendo mais prosperar em um cenário liberal.

Todavia, é de se ressaltar que o direito comparado não é uma disciplina jurídica distinta, pois visa apenas o estudo dos diversos ordenamentos legais, com o fim de aprimorar e completar o direito pátrio de cada Estado, conduzindo à sua precisão na ordem jurídica ${ }^{3}$.

Nunca é demais trazer a ótica autorizada de José Cretella Junior ${ }^{4}$, que ao defender a importância do direito administrativo comparado, conclui:

" $O$ direito comparado conduz a precisão na ordem jurídica e procura erguer a Jurisprudência a mesma altura das ciências exatas.

Evitando o particularismo local, a inexatidão, o aproximado, o mais ou menos, o direito administrativo comparado trabalha com o preciso e o exato, afastando a arquitetônica regional e procurando atingir os modelos universais, para captar os cânones categoriais da Jurisprudência.

Procurando fixar os constantes dos sistemas, uniformiza a terminologia, define os institutos, delineia os sistemas, elimina o supérfluo, procura recorrer, no primeiro momento, a fórmulas exatas do campo universal, flexionando-as, depois, ao particularismo específico de um dado sistema jurídico".

Compartilhamos em gênero, número e grau, com as brilhantes colocações do professor Cretella Junior, que através dos seus robustos posicionamentos é um dos grandes colaboradores ao aprimoramento do direito administrativo no cenário nacional.

Assim sendo, o direito administrativo comparado serve para que o jurista não fique restrito apenas ao direito nacional, pois o "erudito não pode ignorar os trabalhos

1 Eric Agiostini, "Direito Comparado", Tradução de Fernando Couto, Resjuridica, 1ªdiçāo, Porto, p. 6.

2 Jean Rivero não se furtou em chamar o direito administrativo de "primo pobre" ou irmão "caçula" no mundo comparatista (in "Curso de Direito Administrativo Comparado", Tradução de J. Cretella Jr, 1995, RT, p. 31.

3 "O direito comparado não é um ramo do direito, um conjunto de normas unificado por qualquer critério ou elemento. Por isso, os comparatistas pōe regra geral em destaque que a expressão direito comparado não é em rigor adequada para designar a sua disciplina - mais rigorosa é a designação comparação de direitos - é o alemão Rechtsvergleichung - ou semelhantes". (João de Castro Mendes, "Direito Comparado", 1982-1983, editado por Associação Académica da Faculdade de Direito de Lisboa, Lisboa, p. 9).

4 "Direito Administrativo Comparado", 1990, 3ª Edição, Forense, p. 119 
dos estrangeiros sobre um objeto que é o seu..." 5 . É através da comparação de direitos que a doutrina rompe a barreira da fronteira, incorporando normas e aperfeiçoando métodos, sempre em busca de uma melhor definição de valores jurídicos. De igual modo não se pode deixar de advertir que o estudo do direito comparado facilita uma melhor compreensão do direito nacional ${ }^{6}$.

Em suma, a primeira justificativa sobre a função do direito comparado, é a necessidade da evolução, bastando se verificar que como a medicina, a astronomia, a química, a história, a teologia, a economia e todas as demais ciências, ficariam obsoletas se não se unissem à evolução verificada no campo estrangeiro, assim como o direito que cresce com a comparação entre o direito nacional e o sistema jurídico alienígena, nascendo, portanto, a mistura exata para o esgotamento e aprimoramento da matéria ${ }^{7}$. Para Carlos Maximiliano ${ }^{8}$, "todo ramo de conhecimentos se inicia pelo exame e fixação de fenômenos isolados, verificações parciais; na tendência unificadora dos princípios esparsos, na comunidade de representação e de representação e de raciocínio entre seus pensantes está o sinal da objetividade da concepção jurídica; e é na passagem do subjetivo para o objetivo que a idéia, o plano se convertem num sistema; é mediante a generalização que um ramo dos estudos especiais se eleva à categoria de verdadeira ciência".

Destarte, os trabalhos de pura doutrina, de teoria geral, jurisprudência e etc. ao serem confrontados com as teorias nacionais servem de química perfeita para o total aperfeiçoamento da evolução do direito administrativo, que tem sua comparação dos direitos a busca incessante para o jurista não tornar-se prisioneiro do seu próprio direito?.

Tem-se, portanto, que o direito comparado é a garantia de que o direito administrativo estará sempre em plena evolução, possibilitando tempo para o jurista como para o estudioso utilizar-se de instrumentos que são adotados pelas administrações nos variados sistemas existentes, e que podem ser adaptados e empregados pela Administração de cada país.

5 Jean Rivero, "Curso de Direito Administrativo Comparado", RT, 1995, Sāo Paulo, Tradução de José Cretella Junior, p. 18.

6 C.f. Guido Santiago Tawil, "El Estudio del Derecho Comparado y Su Incidencia en el Desarrollo Del Derecho Público Interno", in Revista de Derecho Administrativo, 1991, Ano 3, Depalma, Buenos Aires, p. 79.

7 Em abono ao que foi afirmado, Marc Ancel, aduz: "Fundamentalmente, as ciências exatas originaram-se da comparação das novas disciplinas. Curvier, com as sua liçōes de anatomia comparada (18001805), abriu caminho; falou-se, em seguida, de psicologia, de embriologia, depois de biologia comparada. desenvolveram-se, na Alemanha, pesquisas de gramática comparada e Saine-Beuve impōe, na França a expressão literatura comparada, que se afirma, na Inglaterra, com a publicaçāo da comparative literature de Posnett, em 1876. O transformacionismo de Lamarck, as doutrinas de Darwin repousam sobre a diferenciação dos seres humanos, e a filosofia evolucionista de Herbert Spencer, cuja influência é grande entre os juristas, estende às ciências sociais esta ação das ciências da natureza". ("Utilidade e Métodos do Dierito Comparado", traduçāo de Sérgio José Porto, Fabris Editor, Porto Alegre, 1980, p. 23.

8 "Hermenêutica e Aplicação do Direito", 16a Edição, 1996, Forense, Rio de Janeiro, p. 131.

9 Maximiliano afirma: "Pouco a pouco se foi universalizando, quanto ao Direito, a cultura humana; de um estudo particularista, de fronteiras limitadas, âmbito restrito, passou-se a uma vista de conjunto, ampla, de horizontes vastíssimos" (ob. citada). 
Não se pode, dessa forma, subestimar o estudo comparado do direito, devendo o direito estrangeiro ser dismistificado no intuito de se permitir o pleno conhecimento dos diversos sistemas ${ }^{10}$, onde tentando captar as suas dimensões fundamentais e os seus traços unificadores e compreensivos ${ }^{11}$ se chegará ao resultado esperado, que é o de melhor conhecimento do direito.

Nesse contexto, resulta o estudo do direito administrativo comparado a busca dos seguintes requisitos ${ }^{12}$ :

$\rightarrow$ Confronto dos sistemas administrativos;

$\rightarrow$ Aperfeiçoamento do estudo das instituições, descrevendo-as tais como elas são, sem ficar restrito na aparência legislativa formal;

$\rightarrow$ Investigação das razões históricas, políticas, econômicas e sociais que explicam a estrutura da instituição em cada país;

Por fim, estabelecer a comparação entre os sistemas e extrair daí lição útil para aplicação no direito local.

Assim, o cientista do direito que se utiliza do método comparado deverá se utilizar do estudo o histórico e o meio social pesquisado, para se valer desta confrontação com o fim de incorporá-la, com a devida adaptação ao direito pátrio. Por óbvio que os preceitos estranhos ou incompatíveis com a realidade de um país não poderão servir de parâmetro para uma ilustração, pois a diversidade dos conceitos dificultam a conjugação pretendida com o método da comparação.

A tarefa é árdua, porém gratificante, pois o pesquisador do direito rompe a barreira da fronteira, para trazer modernidade a um determinado segmento do direito, que até então poderia estar adormecido em berço esplêndido, sem contudo, afrontar a ordem jurídica local, que através deste método resulta em exatidão dos princípios em que assenta a pesquisa ${ }^{13}$.

Couture ${ }^{14}$, em "Jornadas de Derecho Comparado" defendia que "la comprensión sucede al conocimento primario, pero procede al conocimento plenário. No

10 C.f. Guido Santiago Tawil, “Administración Y Justiça - Alcance Del Control Judicial de La Actividad Administrativa”, 1993, Depalma, Buenos Aires, p. 6.

11 C.f. Canotilho, "Direito Constitucional”, 1993, 6ª Edição, Almedina, Coimbra, p. 156.

12 C.f. Marcelo Caetano, "Manual de Direito Administrativo", 1991, Tomo 1, 10ª Edição, Almedina, Coimbra, p. 62.

13 Carlos Maximiliano, deixou-nos a feliz idéia de que: "O Processo Sistemático, levado às suas últimas consequiências, naturais, lógicas, induz a por em contribuição um elemento moderníssimo - o Direito Comparado. Efetivamente, deve confrontar-se o texto sujeito a exame, como os restantes, da mesma lei ou de leis congêneres, isto é, com as disposiçōes relativas ao assunto, quer se encontrem no Direito Nacional, quer no estrangeiro; procura-se e revela-se a posição da regra normal no sistema jurídico moderno, considerado no seu compelxo". ("Hermenêutica a Aplicaçāo do Direito", 16a Ediçāo, 1996, Forense, Rio de Janeiro, p. 131)

14 J. Couture, "Jornadas de Derecho Comparado", 1955, publicaçāo del Centro de Estudios de Derecho Comparado, Montevideo, p. 38. 
podemos comprender sin conocer algo; pero no podremos nunca conocer todo $\sin$ haberlo comprendido en sus esencias. El derecho comparado es un instrumento de comprensión de los pueblos, porque el derecho es la historia escrita de un pueblo. Es posible que al lado de sus leyes, que son conducta prevista, se hayan desenvuelto otras conductas efectivamente vividas. Las sentencias de los jueces no siempre dicen lo que las leyes pronostican, ni toda la conducta de los cuidadanos se rige por las sentencias de los jueces. Pero; cuántas veces la leyes de um pueblo nos revelan sus estados de conciencia, sus anhelos y sus defallecimientos ! Por la misma razón por la cual conocer la ley no es comprender la ley, podemos admitir que conocer el derecho de un pueblo no significa comprender ese pueblo. Pero si algún día de nuestra vida podemos llegar a comprender las leyes de un pueblo, podemos tener cierta esperanza de llegar, con un poco más de esfuerzo, a comprender al pueblo mismo".

Por isso é que mediante a comparação da vários sistemas em que atuam normas administrativas, pode-se aperfeiçoar o campo de aplicação do direito local, que possui o alicerçe deste instrumento para não ficar em compasso de espera. $O$ professor Rafael Bielsa ${ }^{15}$ foi um dos seguidores da comparação de direito público, ao citar Saleilles, sublinha:

"2. O direito comparado tem por objeto, enquanto é ciência auxiliar, serve ao desenvolvimento progressivo do direito nacional, oferecendo um fim positivo, seja pela evolução legislativa, seja pelas construções doutrinadas, seja pela interpretação jurisprudencial.

3. A medida em que pode ser admitida esta influência do direito comparado, em matéria de interpretação, depende de concepções aceitadas como dominantes em matéria de interpretação jurídica e pode variar segundo os diferentes ramos do direito".

O cultor do direito administrativo comparado atualmente possui a facilidade de não precisar dominar algumas línguas do mundo ocidental (inglês, espanhol, francês, italiano, português e alemão), em razão de existirem traduções das obras clássicas e importantes, que de certa forma desinibem o jurisconsulto, pois através da sua língua pode acessar o pensamento estrangeiro. Principalmente na língua espanhola, que não é difícil de se compreender, existem as mais variadas traduções que facilitam e permitem o acesso aos que não dominam o francês, alemão, italiano, português e etc. Infelizmente, por não ser tão comercial, nossas editoras não se interessam em promover traduções de trabalhos imperiosos para o aprimoramento do direito comparado, exigindo do cultur desta área que importe os livros necessários para a busca incessante da evolução de se comparar coisas comparáveis' ${ }^{16}$, constatando-se o velho brocado: dura lex sed lex positivista legalista ("divertida justiça que muda os paralelos").

15 In "Estudios de Derecho Publico I, Derecho Administrativo", 1950, Buenos Aires, p. 55.

16 Paul Koschaker, "L'historie du droit et le droit comparé vurtout en Allemagne, em Recueil Lambert", 1938, Vol. I, p. 280. 
Na feliz dicção do mestre francês Eric Agostini" ${ }^{17}$ " além do interesse prático, do formativo e da sua contribuição para a polêmica eterna da ontologia e do fundamento do Direito, a Comparação de Direitos é ainda uma matéria cultural do maior interesse, apta a cativar qualquer honnête homme".

O desenvolvimento do comércio internacional, a facilidade das relações humanas, o crescimento e evolução dos meios de comunicações aproximaram os povos e as suas culturas, surgindo no exterior uma sociedade de legislação comparada, notadamente na França, em 1869, cuja criação foi considerada como símbolo do surgimento do direito comparado ${ }^{18}$, sendo que após a $2^{\mathrm{a}}$ Grande Guerra Mundial os povos se aproximaram, através de uma unificação de interesses viu-se a necessidade de entrelaçamento das relações jurídicas, em busca de um relacionamento melhor, onde a justiça social e a liberdade de expressão se engajavam na democracia mundial, ficando o mundo sub-dividido no Bloco Comunista e no Capitalista, sendo que o primeiro atualmente aderiu ao segundo.

Com a unificação dos povos, que atuam em blocos e constituindo o direito, reflexo do modelo da ordem social para a qual está vocacionado, se verifica que houve diminuição das diferenças contidas nas regras jurídicas de um país para o outro, como consequiência da respectiva união, adquirindo o direito comparado força congente que há muitos anos não ocorria. Isto porque, a importação das regras administrativas deu-se em um primeiro momento com grande intensidade quando da evolução histórica deste ramo do direito, que ficou sobrestado no período seguinte, marco do crescimento nacional, onde as fronteiras do conhecimento externo ficaram fechadas por alguns anos. Entretanto, como o direito é a ciência que cresce em passos largos, evoluindo diariamente, pois necessita acompanhar a evolução dos conceitos que regerm a própria sociedade, o direito comparado voltou a ocupar o lugar de destaque que merece, pois através da globalização da economia o mundo moderno, espera a vinda do terceiro milênio menos distante no campo social e dos direitos. Através da comparação de direitos, os obstáculos do desconhecido se tornam ultrapassados, vivenciando o mundo a unificação de regras e princípios jurídicos que permitem maior aproximação dos povos ${ }^{19}$.

E Santiago Dantas, na sua vetusta cátedra ensinava que o direito comparado conqusitou definitivamente a doutrina nacional, que através do método da comparação legislativa possibilitou o florecimento do estudo do direito estrangeiro ${ }^{20}$, dirigido ao conhecimento da evolução interna de cada sistema.

17 Eric Agostini, "Droit Comparé”, traduzido por Paulo Ferreira da Cunha, Colecçāo Res Jurídica, sem data, Porto, p. 6.

18 Cf. Marc Ancel, “Utilidade e Método do Direito Comparado", traduzido por Sérgio José Porto, Fabris Editora, Porto Alegre, 1980, p. 21).

19 "Falando de unificaçāo do direito para significar o esforço dos juristas dirigidos à uniformização das ordens jurídicas diferentes (e ao lado da uniformização consideramos as finalidades paralelas de aproximação e de harmonização), já o esforço de obter um resultado tão vasto quanto possível é evidentemente possível. Poderíamos dizer mesmo mais, em jeito de paradoxo o esforço de atingir o impossível é possível". (João de Castro Mendes, "Direito Comparado", 1982-1983, Associação Acadêmica Lisboa, Lisboa, p. 87).

20 "Revista Forense", março de 1948, p. 11. 
Para finalizar esta parte introdutória, nunca é demais ressaltar que o direito comparado foi adotado em todo o mundo ${ }^{21}$ jurídico evoluído, correspondendo nas diversas línguas: droi comparé, diritto comparato, derecho comparado, direito comparado, drept comparat, comparative law, vergleichendes recht ou rechttsverglichung, sravnitelnoiéprovo, oszelhasonlitó jog.

\section{Estudo comparado do direito público e a sua aplicação no direito interno}

"As árvores escondem a floresta. Os cânones locais dificultam-lhe a visão panorâmica dos grandes momentos categoriais das matrizes da jurisprudência. $O$ fenômeno jurídico deixa de ser universal para vincular-se às restritas cogitaçōes locais."

\section{(José Cretella Junior)}

Considerado como um produto peculiar da história de cada povo, o direito administrativo conservou durante algum tempo um carater estritamente nacional ${ }^{22}$. Com a constante evolução deste novo ramo do direito e a crescente influência de outros sistemas na estrutura administrativa interna das distintas nações - visível, por exemplo, com a recepção de instituições tais como o Conselho de Estado na Itália, Grécia, Portugal e Bélgica; e o ombudsman escandinavo na França, Grã-Bretanha e Itália e na codificação do procedimento administrativo na Alemanha, Etados Unidos, Espanha, Áustria e na Argentina - modificaram, em algum sentido a visão unitária, posto que a diversidade de direitos possibilitou a devida complementação jurídica, adaptada a cada realidade.

Em algumas nações jovens como por exemplo o Brasil, a influência do direito público estrangeiro foi crucial para o início da conceituação básica e aplicação do direito constitucional e administrativo ${ }^{23}$ local. A Constituição de 1891 sofreu influência do direito norte-americano, onde o "Juridiciarismo" prevaleceu, cabendo a Justiça, em especial ao Supremo Tribunal Federal, a última palavra na interpretação constitucional, além da garantia do remédio do habeas corpus ${ }^{24}$ capaz de garantir a

21 C.f. Cretella Junior, “Direito Administrativo Comparado", Forense, p. 76. O ilustre mestre afirma que de um modo mais simples e objetivo, o direito administrativo comparado é o método jurídico pelo qual se colocam em confronto: "(a) instituições, (b) direitos ou (c) sistemas".

22 C.f. Guido Santiago Tawil, “El Estudio Del Derecho Comparado Y Su Incidencia En El Desarrolo Del Derecho Publico Interno", in Revista de Derecho Administrativo, 1991, Ano 3, Depalma, Buenos Aires, pp. 73/74.

23 A primeira obra nacional sobre direito administrativo veio no Império, em 1862, de Paulino José Soares de Souza, Visconde do Uruguai, como descritor dos "Estudos de Direito Administrativo", Vols. I e II, tendo como ponto de apoio a base comparatista, e levando-se em consideração "a prática da administração", com exposição positiva e metódica de toda legislação administrativa, analisando os respectivos defeitos e lacunas e propondo melhoramentos e reformas (c.f. Haroldo Valladão, "História do Direito Especialmente do Direito Brasileiro", $4^{2}$ Edição, Freitas Bastos, 1980, p. 138).

24 Art. 72, $\$ 2^{\circ}$ da Constituição Política do Império do Brasil de 1891, estipulava: "Dar-se-à habeas corpus, sempre que o indivíduo sofrer ou se acabar em iminente perigo de sofrer violência ou coação por 
liberdade individual de locomoção. Devendo também ser ressaltado que o desvio de poder da Administração, como por exemplo, a violação da lei, do direito adquirido, da incompetência do agente e o vício de forma do ato administrativo, foram incorporados do direito francês, permanecendo entranhados nos nossos ordenamentos pátrios, como norma eficaz no combate dos excessos.

Sobre a supremacia do Poder Judiciário, a maior contribuição americana ao direito constitucional nasceu pela firme posição do Juiz Marshall, que no famoso caso Marbury v. Madison, impôs o controle da constitucionalidade das leis pelo judiciário, consoante objeto de copiosa bibliografia. Este princípio permitiu que fossem questionados atos administrativos praticados contra os princípios assentes na Constituição. As circunstâncias do caso podem ser assim muito ligeiramente sumariadas: Marbury foi legalmente nomeado, em 1801, nos últimos dias do governo de Adams, como Juiz de Paz do Distrito de Columbia. Madison, que ocupava o cargo de Secretário do Governo, seguindo orientação de Jefferson, o novo Presidente, negou-lhe a posse. Interposto mandando de segurança contra Madison, ele não se defendeu e deixou a causa correr à revelia. Em 1802, nos jornais e no Congresso foi a Suprema Corte violentamente atacada, no intuito de pressioná-la para negar o writ, sendo sugerido por James Monroe o impeachment contra os seus juízes se eles ousassem "aplicar os princípios da common law à Constituição". Como relata Leda Boechat Rodrigues ${ }^{25}$, mesma providência foi pleiteada, dias antes da decisão, por um jornal oficioso do governo, o Independent Chronicle, de Boston, segundo o qual a concessão da medida significativa "guerra entre os departamentos constituídos". Se concedida, a medida certamente não seria cumprida.

Todavia, apesar da difícil situação, indeferir simplesmente o pleito seria uma fraqueza grande do Judiciário, que como Poder independente ficaria totalmente desacreditado. Foi então, através de uma hábil manobra, que a Corte decidiu ${ }^{26}$ : "Madison, na realidade, agira ilegalmente ao negar posse a Marbury; e, de acordo com os princípios aplicáveis da Commom Law, havia remédio para tal caso, o mandamus, pelo qual Madison poderia ser compelido a dar posse a Marbury. Não cabia porém, o writ, porque pedido diretamente à Corte Suprema cuja competência

ilegalidade ou abuso de poder". E coube a Rui Barbosa ser o grande propagador brasileiro do instituto do habeas corpus discursando no Supremo Tribunal Federal, em 26 de março de 1898: "O homem privado da liberdade jaz em estado pior do que a morte, porque sente em si todo o amargor da opressāo e, ao mesmo tempo, toda a importância do morto a evitá-la. A condição desse indivíduo reclama, por isso, a mais viva solicitude e a mais valente defesa social. Nenhum cidadão honesto pode ser indiferente à própria segurança. Na faculdade de prender, ou nāo prender o cidadão, parece estar o ponto central, onde praticamente se vão encontrar todos os raios da tirania, ou da liberdade. Eis senhores juízes, de onde resulta a suprema importância do habeas corpus entre as nações livres. As outras garantias individuais contra a prepotência são faculdades do ofendido. Esta é dever de todos pela defesa comum... A liberdade não entra no patrimônio particular, como as coisas que estão no comércio, que se dão, trocam, vendem, ou compram: é um verdadeiro condomínio social, todos as desfrutam, sem que ninguém o possa alienar..." ("O Habeas Corpus. O Estado de Sítio. Tema de Seus Efeitos" in "Escritos e Discursos Seletos"), Editora Nova Aguilar, 1995, p. 497.

25 In "A Corte Suprema e o Distrito Constitucional Americano", 1958, Forense, Rio de Janeiro, p. 36. 26 Ob. citada. 
originária era estritamente definida na Constituição e não podia ter sido dilatada pela Lei Judiciária de 1789. Era assim, inconstitucional e nulo o Art. 13 dessa lei, que atribuía a Corte Suprema competência originária para expedir ordens de mandamus".

Foi proclamado, assim, que a Corte poderia interferir nos textos legislativos contrários a Constituição, demonstrando que a interpretação das leis terá que ser in harmony of the Constitucion. Apesar de ter recuado ao confronto com o Chefe do Executivo, ao declarar inconstitucional o Art. 13 da Lei Judiciária de 1789, visava Marshall fim meramente político, demonstrando, através da discussão do mérito, haver Jefferson cometido uma ilegalidade, mas falecia ao Tribunal, por uma questão preliminar, de competência, determinar a correção.

Voltando ao núcleo central, se constata que o writ of mandamus também foi importado do direito alienígena, tornando-se grande arma contra a ilegalidade ou abuso de poder da autoridade pública ou agente de pessoa jurídica no exercício de atribuições do Poder Público, vindo a fazer parte da Constituição de 1934 (Art. 113, 33).

$\mathrm{Na}$ seqüência dessas influências, surgiu um outro princípio básico da estruturação do Estado, vindo do sistema da revolução francesa, que é o princípio da legalidade $^{27}$, que tem como fundamento teórico na tradição da doutrina inglesa de luta contra a arbitrariedade da monarquia absoluta. Este princípio guarda tanta relevância para o nosso direito administrativo que foi alçado à órbita constitucional notadamente no caput do Art. 37.

A par deste contexto, não resta dúvida de que a comparação de princípios verificados em outras codificações permitiu a utilização de consagrados princípios que incorporam-se em diversas naçōes. A história autoriza afirmar que no direito administrativo houve sistematização de determinados princípios, que ao se incorporar se integraram ao direito pátrio de cada país. Somente através do direito comparado é que estes princípios universais poderiam despontar, ligando as nações pelo direito que proclamam e reconhecem que as suas administrações são submetidas ao direito, que segundo a terminologia alemã, todas se curvam ao Rechtsstaat em oposição ao estado de força (Polizeistaat), se devendo esta contribuição à Gneist, no tocante a terminologia.

A regra do due process of law foi efetivamente incorporada ao direito administrativo nacional, por submissão ao atual Inc. LV do Art. 5 da Constituição Federal, que garante aos acusados em processo judicial ou administrativo o contraditório e a ampla defesa, com os meios e recursos a ele inerentes. Significa dizer, que qualquer irregularidade a ser apurada, até mesmo na fase da sindicância, deverá ser dada oportunidade ao investigado de se defender, para após ser lucidamente decidido se haverá o não abertura de inquérito administrativo, que também deverá garantir ao servidor público a utilização da ampla defesa como bandeira de atuação da Comissão,

27 Sobre o tema, Eduardo Garcia de Enterría, afirma: "La primeira de estas ideas, el principio de legalidad, constituye, desde luego, un instrumento directamente lanzado contra la estructura política del Estado absoluto: frente al poder personal y arbitrario. el ideal del Gobierno por y en virtude de las leyes".

"Revolucion Francesa y Administracion Contemporanea", 4" Edição, 1994, Civitas, Madrid, p. 21. 
sob pena de ser natimorto o procedimento aberto. Esta é a nova regra constitucional, que importou este princípio relevante dos Estados Democrátcos de Direito, sendo obrigatório o respeito ao princípio da ampla defesa até mesmo nos casos em que a Comissão de Sindicância determinar a pena de advertência ao servidor, conforme se verifica na Orientação Normativa da SAF n. 97 (DOU de 02.05.91). Como o tema é de grande relevância, discorremos sobre o mesmo em tópico próprio, para não desviar do foco de atenção do estudo comparado do direito administrativo e sua aplicação ao direito interno.

É portanto, de grande relevância o direito comparado, que serve de modelo para a adaptação e criação legislativa nacional, como por exemplo a contribuição romanística sobre personalidade jurídica dos entes de direito público criados para descentralizar o Poder, os quais col aboram na concretização dos serviços públicos, tendo os mesmos personalidade jurídica e financeira própria, refletindo influências também do direito francês e do direito italiano.

Coube, dessa forma, ao direito brasileiro, por influência dos nossos juristas, adaptar a terminologia ítalo-francesa e adaptá-la ao direito pátrio aos conceitos expressos pelos vacábulos "autarquia", " paraestatal", "estabelecimento público", "ente territorial" e "ente não territorial", "beneficiando-se, desse modo, com a experiência dos grandes centros europeus, o que não ocorre com os juristas desses mesmos centros, por demais isolados nos próprios sistemas e muito ciosos de sua importância para poderem editar mais aprimorados dos direitos vizinhos" ${ }^{28}$.

Outro princípio importado pela doutrina nacional ${ }^{29}$ ao direito estrangeiro, e com ampla aplicação nos nossos tribunais é o princípio da proporcionalidade ou razoabilidade das leis, que filia-se à regra da observância da lei ao princípio da finalidade que deve reinar no âmbito da Administração Pública ${ }^{30}$.

Exemplo claro e robusto deste princípio vem espelhado no recente e brilhante voto do Ministro Marco Aurélio, no Recurso Extraordinário n. 192568-0 Piauí, onde o proficiente julgador anulou concurso público feito no prazo de validade do anterior que ainda possuía estoque de candidatos para preenchimento das vagas existentes, ficando assim ementado o aresto ${ }^{31}$ :

28 J. Cretella Junior, in "Direito Administrativo Comparado", 1990, Forense, Rio de Janeiro, p. 220.

29 Ler a respeito do tema, "Revista de Direito Administrativo", Abril/Junho 1996, 204, Caio Tácito, "A razoabilidade das Leis", Editora Renovar; Raquel Denize Stumm, "Princípio da Proporcionalidade no Direito Constitucional Brasileiro", Editora Livraria do Advogado, Porto Alegre, 1995 e Suzana de Toledo Barros, "O Princípio da Proporcionalidade e o Controle de Constitucionalidade das Leis Restritivas de Direitos Fundamentais", 1996, Ed. Brasília Jurídica e "Razoabilidad de Las Leyes", Juan Francisco Livares, $2^{\mathbf{2}}$ Edição, Astrea, Buenos Aires.

30 "O controle de razoabilidade das leis mediante um parâmetro técnico dado pelo princípio da proporcionalidade representou uma virada científica de grande repercussão junto aos países europeus que adotam controle jurisdicional de constitucionalidade, como Portugal, Espanha, Itália e Áustria, irradiando-se mais recentemente ao Brasil, por intermédio da forte influência dos constitucionalistas portugueses na doutrina e jurisprudência nacionais". Suzana de Toledo Barros, "O Princípio da Proporcionalidade e O Controle de Constitucionalidade das Leis Restritivas de Direitos Fundamentais", Ed. Brasília Jurídica, p. 45.

31 STF, 2a Turma, Rel. Ministro Marco Aurélio, no Recurso Extraordinário n. 192568-0 Piauí, julgado em 23.04.96. 
Concurso Público - Vagas - Nomeação. O princípio da razoabilidade é conducente a presumir-se, como objeto do concurso, o preenchimento das vagas existentes. Exsurge configurador do desvio de poder, ato da Administração Pública que implique nomeação parcial de candidatos, indeferimento da prorrogação do prazo do concurso sem justificativa socialmente aceitável e publicação de novo edita com idêntica finalidade.

Como o Inciso IV (do Artigo 37 da Constituição Federal) tem o objetivo manifesto de resguardar precedências na seqüência dos concursos, segue-se que a Administração não poderá, sem burlar o dispositivo e sem incorrer em desvio de poder, deixar escoar deliberadamente o periodo de validade de concurso anterior para nomear os aprovados em certames subseqüentes. Fora isto possivel e o Inciso IV tornar-se-ia letra morta, constituindo-se na mais rúptil das garantias" (Celso Antonio Bandeira de Mello", Regime Constitucional dos Servidores da Administração Direta e Indireta", página 56).

Pelo princípio da razoabilidade ou proporcionalidade, o ato administrativo fica ainda mais atrelado ao rigor da finalidade, como instrumento de proteção ao administrado, que não pode sofrer tratamento que deságüe no desvio do poder por parte da Administração Pública.

Pela compreensão de um exame comparativo do direito público pode resultar tanto uma fonte saudável de respostas como de fecunda inovação, questionando inclusive erros cometidos. É através da comparação do direito administrativo, que o estudioso possibilita a sua aplicação no direito interno, desde que não haja conflito legal para tal utilização como fonte de inspiração do direito contemporâneo ${ }^{32}$.

E Tawil ${ }^{33}$, com a sua autorizada visão, em curtas, porém sólidas palavras afirma que "el estudio del derecho extranjero puede desde las instituciones locales, conspirando contra la determinación de lo que es o deberia ser el derecho público patrio".

Parece inquestionável que a ciência jurídica não fica enclausurada dentro da fronteira de um Estado, tendo em vista que o nacionalismo jurídicio representa verdadeiro empobrecimento do ordenamento interno, que como ciência possui no estrangeiro a fórmula que permite a comparação das técnicas, visando sempre o crescimento e aperfeiçoamento necessário para a constante evolução do direito público, que através da integração internacional, sente a necessidade da transcendência da fronteira, para a verdadeira sistematização dos direitos administrativos.

A atual identidade da comparação de direitos está vinculada à coesão econômica e social do mundo contemporâneo, que através de comunidades traçam os seus objetivos institucionais, tendo em determinados casos regras e condutas próprias

32 A respeito, Guido Santiago Tawil, não tem dúvida em afirmar: "En efecto, si bien las ideas extranjeras constituyen una fuente de inspiración innegable de innumerables principios e instituciones del derecho administrativo contepomráneo, no se trata, por cierto, de transplantarlas, artificialmente, al contrario, de conocerlas, examinarlas y aprender de ellas a fin de tomar lo positivo y desechar aquellas concepciones apenas o inconvenientes para nuestro sistema jurídico". ("Revista de Derecho Administrativo", 1991, Ano 3, ns. 6 a 8, Depalma, Buenos Aires, p. 80).

33 Ob. citada, p. 81 . 
para os países membros, aumentando a competividade internacional. Somente com a identidade de direitos é que se possibilita o mecanismo da atuação em bloco, onde o objetivo comum é o fortalecimento das bases comerciais, científicas e tecnológicas e etc.

Nota-se, portanto, uma relevância grande no campo do direito público comparado, que através da unificação de blocos de países, incorporam preceitos legais de interesse comunitário, com o objetivo de diminuir as desigualdades, possibilitando a equilibrada evolução do direito administrativo.

Estreitamente ligado ao movimento de unificação do direito, e com ele integrado no princípio de internacionalização, surgem os tratados e as convenções que dizem respeito ao direito privado e processual civil e penal ${ }^{34}$.

Sob o prisma internacional, coube a Corte de Haia criar convenções para resolver pacificamente os litígios entre as nações. Definitivamente, outro elemento que favorece os que defendem a importância do direito comparado como forma de robusta consulta. E não se deve esquecer que em 1890 , quando da promulgação do Novo Código Civil Alemão (B.G.B), a escola histórica, afirma do grande avanço desta codificação ${ }^{35}$, em relação ao ato jurídico, à declaração de vontade, o papel da boa-fé, e até nos casos de regras legais aplicáveis a situações especiais, tais como a vinculação do filho ilegítimo à sua mãe ou a transferência de propriedade pelo contrato de venda ${ }^{36}$. Sendo que o nosso Código Civil seguiu o compasso das inovações surgidas pela edição do B.G.B., que na série da prospecção comparativa, importou regras e fundamentos que seguem as relações provadas até os dias de hoje. Como não poderia deixar de ser, o direito público, como já dito alhures, também é fruto de comparações, resultando do emprego espontâneo e necessário deste método para alcançar seu importante espaço no cenário internacional, de maneria que ocorra perfeita harmonia entre os povos, permitindo que seja superada "a simples formulação da norma escrita, como a única consideração da lei territorial ou da técnica jurídica específica" ${ }^{37}$.

Nesse contexto, o Estatuto do Tribunal Internacional de Justiça, no seu Art. 38, determina que se apliquem aos litígios sujeitos à sua jurisdição, na falta de outras fontes, os "princípios gerais de direitos reconhecidos pelas nações civilizadas"; e o Art. 215 do Tratado de Roma, que institui a Comunidade Européia, os "princípios gerais comuns aos direitos dos Estados membros".

No plano Civil a irradiação do Código Civil francês de 1804, "Code Napoléon", é inegável, servindo de modelo para os diversos Códigos da Europa Ocidental, sendo que na América do Sul o Código-base foi o argentino, colocado em prática em 1869, tendo como idealizador Velez Sarsfield.

Nesse diapasão, o Código Civil Suíço foi adotado e promulgado na Turquia em

34 Cf. João de Castro Mendes, ob. Citada, p. 97.

35 Cf. Marc Ancel, "Utilidade e Métodos do Direito Comparado", traduzido por Sérgio José Porto, Fabris Editor, Porto Alegre, 1980, p. 32.

36 Ob. citada.

37 Ob. citada, p. 141. 
04 de abril de 1926, colocado em vigor seis meses mais tarde, ou seja, em 04 de outubro daquele ano. Sucedeu o mesmo com o Código das Obrigações Suíço, que foi promulgado em 08 de maio de 1926 e posto em prática na mesma data que o Código Civil.

Portanto, pelo estudo e prática do direito comparado os povos quebram barreiras e encurtam as fronteiras, possibilitando a verdadeira unificação dos mesmos.

\section{Direito comparado como método de estudo}

“...el estudio del derecho comparado importa una ampliación significativa del horizonte jurídico de los especialistas".

(Guido Santiago Tawil)

O caráter instrumental que reveste o estudo comparativo do direito não deve conduzir o intérprete a subestimar as implicaçōes acadêmicas e profissionais na aplicação da ciência jurídica e em particular no direito administrativo.

No cenário nacional, o insígne mestre José Cretella Junior foi o responsável pelo Curso de Pós-Graduação em Direito Administrativo, programado para 3 (três) anos ou 6 (seis) semestres, num total de 12 (doze) aulas por semestre, brindando-nos com uma obra específica sobre a matéria ${ }^{38}$, que reproduz a visão moderna e eficaz do direito administrativo comparado, que ainda não havia merecido nenhum livro nacional sobre o tema, tendo vasta bibliografia de outros países, banindo a lacuna existente no direito pátrio.

Desnecessário afirmar a grande importância de Cretella para os comparatistas do direito administrativo, que não só deixaram de ser órfãos na matéria sub-oculis, como foram agraciados com a tradução do "Curso de Direito Administrativo Comparado" ${ }^{39}$, de Jean Rivero feita pelo citado professor, que através de uma bibliografia atual, permite maior difusão na comparação do direito administrativo.

No Brasil, o direito comparado, como não é ramo do direito, não figura nos curriculuns universitários, merecendo pouco destaque no cenário jurídico nacional. Porém, com a integração dos povos e a necessidade de uma ampliação significativa do horizonte jurídico dos especialistas, está ocorrendo uma procura mais intensa dos títulos estrangeiros ${ }^{40}$.

Isto se dá também pela abertura do mercado de livros, onde se encontram trabalhos magistrais nas livrarias tradicionais, que através da importação possibilitam

38 "Direito Administrativo Comparado", Forense, 1990, São Paulo.

39 Editora RT, 1995.

40 Especificamente sobre o cenário nacional, Maximiliano aduz: "No Brasil, como em toda parte, ao emendar Textos Constitucionais, ou elaborar leis ordinárias, claudicam os parlamentares com traduzir textos positivos se compulsar a obra dos comentadores eruditos. Quem lê unicamente Código ou Constituição tem uma só base, a mais fraca - a exegese verbal: faltam-lhe os demais, e os melhores, elementos de interpretação; por isso, toma com freqüência a nuvem por Juno, desgarra a valer". (ob. citada, p. 133). 
o acesso aos leitores dos posicionamentos autorizados de grandes doutrinadores estrangeiros, que contribuem de forma concreta com a comparação dos horizontes administrativos, em busca de recurso ou auxílio de instituições similares de outros povos visando descobrir os fins que perseguem ao analisar as suas próprias leis em função delas. Pela internet também se adquire os livros necessários à comparação de direitos ${ }^{41}$.

Assim, no campo do direito administrativo, por exemplo, a importância atribuída à Alemanha no estudo da comparação com o direito francês traz o esforço de Otto Mayer, prolongados pela doutrina contemporânea em obras de grande valia, que construiram o recente direito administrativo europeu, como por exemplo o trabalho do professor Jurgen Schwarze, publicado no ano de 1988.

Não resta dúvida que pelo método "comparatista", o direito comparado é utilizado em numerosas ocasiões, sempre em busca de investigação para uma aproximação com o direito interno, através da confrontação da legislação e do estudo da sua evolução, respostas até então obscuras, harmonizando os distintos sistemas jurídicos em busca não só da unificação internacional do direito, como também para que haja a manutenção do progresso da nossa civilização. Triste seria a civilização que fosse sub-dividida em territórios incomunicáveis, sem contato com o mundo exterior, sem integração dos povos, e lacrada em conceitos próprios. Seria um universo não tão fecundo nas suas descobertas, ficando involuído e estagnado.

Assim, pela compreensão do exame comparativo do direito público se obtém as respostas que são condições sine qua non para a evolução do sistema jurídico nacional, transcendendo possíveis erros cometidos em um passado, como por exemplo a utilização da regra do due process of law na sindicância administrativa, onde o servidor acusado possui o direito de se defender das imputações ou fatos tidos como apuráveis pela Administração. Tal ótica não era a prevalente pela regra encartada pela Lei 1.711/52, que foi revogada e deu espaço para a modernidade.

Com efeito, como sublinha Tawil ${ }^{42}$, “...las ideas extranjeras constituyen una fuente de inspiración innegable de innumerables principios e instituciones del derecho administrativo contemporáneo; no se trata, por cierto, de trasplantarlas artificialmente sino, al contrario, de conocerlas, examinarlas y aprender de ellas a fin de tomar lo positivo y desechar aquellas concepciones ajenas o inconvenientes para nuestro sistema jurídico".

E, sobre o confronto de "ramos do direito", Cretella ${ }^{43}$ averba: "Assim como se pode fazer o confronto de institutos, pode-se igualmente proceder ao confronto de ramos do direito. Podemos comparar o direito penal brasileiro com o direito penal inglês, o direito administrativo pátrio com o direito administrativo francês. Por exemplo, o confronto entre dois direitos administrativos, a saber, um direito qualquer do sistema do common law, ou, de um modo mais concreto e específico, o direito francês e o direito inglês, vai revelar vários traços que se percebe, na comparação,

41 www.magic-es.com/marcialpons/; www.liv-arcoiris.pt; www.bemarnet.es/rgd/homepage.s. html;

42 "El Estudio del Derecho Comparado", RDA, 1991, Ano 3, Depalma, Buenos Aires, p. 80.

43 Ob. citada, p. 19. 
a presença de duas realidades, de dois mundos, de dois tratamentos, de duas técnicas, de dois regimes diversos: (a) dualidade e unidade de jurisdição, (b) responsabilidade e irresponsabilidade civil do Estado, (c) auto-executoriedade do ato administrativo, (d) regime estatutário e regime trabalhista do agente público, (e) irrelevância e relevância do precedente", e mais a frente, no confronto de "direitos", afirma o citado mestre 4 : "Pode-se, em terceiro lugar, fazer o confronto global de direitos: "direito inglês" e "direito soviético", "direito brasileiro" e "direito francês". Nesses casos, pode-se principiar pela ala do direito público ou pela da do direito privado, descendo-se do gênero às espécies, ramo a ramo até chegar-se a uma visão global e panorâmica dos direitos confrontados".

Como os juristas são responsáveis pela interpretação da lei administrativa ${ }^{45}$, é natural que adquiram visão ampla da ciência estudada, tendo em vista que a ciência "é feita de adição por colaboração" ${ }^{46}$, sendo certo, que sem a comparação do direito administrativo, não haveria o progresso, pois a estagnação jurídica seria elemento de freio da integração dos povos. Em um país que não possui abundante literatura jurídica como o nosso, os intérpretes procuram na doutrina estrangeira os princípios gerais de determinado instituto, de certa disciplina ou de todo sistema jurídico. Esse fato se configura com maior intensidade no direito administrativo, que durante muitos anos foi pouco cultivado, seguindo a esteira das indicações da França.

O progresso do estudo comparado de direito depende substancialmente dos contatos dos especialistas, que podem se concretizar com a renovada bibliografia colocada à disposição do jurista, ou da realização de conferências, palestras ou seminários.

Não resta dúvida que coube aos estados europeus, em meados do Século XIX, com a aparição da matéria "Legislación Comparada" ${ }^{47}$ a criação das primeiras sociedades dedicadas ao seu estudo ${ }^{48}$.

Já na América do Sul, a Faculdade de Direito e Ciências Sociais da Universidade de Buenos Aires teve a iniciativa de, há mais de 8 (oito) décadas incluir o "Direito Administrativo Comparado" como disciplina autônoma dentro dos planos curriculares, incluso no sétimo ano (doutorado) ${ }^{49}$. De forma lamentável, sem nenhum motivo aparente, o estudo do direito administrativo comparado na Argentina, foi perdendo o interesse entre os especialistas daquele país, sendo excluído este ramo da ciência jurídica dos meios universitários.

44 Ob. citada.

45 Marcello Caetano, "Manual de Direito Administrativo", Vol. I, 10ã Edição, 1991, Almedina, Coimbra, p. 124.

46 Cretella, ob. citada, p. 125.

47 Tawil, ob. citada, p. 74.

48 Como a "Sociedade de Legislaçāo Comparada", criada na França em 1869, a qual fez referência ao professor René David e sua clássica obra titulada "Los Grandes Sistemas Jurídicos Contemporáneos (Derecho Comparado)", trad. da $2^{2}$ edição francesa, Agulilar, Madrid, 1969, p. 4.

49 "Anales de La Facultad de Derecho Y Ciencias Sociales". T. I, 2 serie (1911), pp. 650/51, citado por Rafael Bielsa in "El Estudio del Derecho Comparado en la Enseñanza del Derecho Público Interno (ideas generales), in Estudios de Derecho Público. Derecho Administrativo", Tomo I, 2a Edição, Depalma. Buenos Aires, 1950, p. 54. 
Para suprir o vácuo deixado, recentemente foi incluído no curso de Pós-Graduação em Direito Administrativo, em 1991, a "introducción de la matéria "Derecho Administrativo Comparado" 50.

Por outro lado, a importância do surgimento da ciência jurídica comparativa é inegável, tendo na França o seu início, com a formação de uma Sociedade de Legislação Comparada, em $1869^{51}$. Neste mesmo ano, foi criado na Inglaterra, em Oxford, a primeira cadeira de direito comparado, "Historical and Comparative Jurisprudence" 52 , confiada ao Sir Henry Summer Maine. Na Bélgica se fundou nesta época a Revue de Droit Internacional et de Droit Comparé.

Até mesmo no Japão, em 1868, foi aberta a era da ocidentalização (Meiji), onde se verifica que houve tradução dos códigos franceses para servir de base à uma codificação moderna e em que as universidades recebecem os primeiros juristas ocidentais, modernizando o antigo sistema jurídico existente.

Consagrando de vez a comparação de direitos, na virada do Século XX, em Paris, no ano de 1900, houve a Exposição Universal da Sociedade de Legislação Comparada, onde os maiores juristas da época se fizeram presentes. Por certo que na França, país precursor do direito administrativo comparado, existe a publicação periódica da Revue Internationale de Droit Comparé, que teve o primeiro exemplar circulado em 1877 com o nome de Bulletin de la Sociéte de Législations Étrangères, sendo que em 1948 é que ficou com o título atrás indicado, possuindo o condão de manter acesso à comparação de direitos no continente europeu.

Bielsa $^{53}$ discorrendo sobre a planificação dos estudos da Faculdade de Direito da Universidade de Paris, deixou registrado que são exigidos no curso de doutorado: "Assim, para o diploma de estudos superiores de direito privado (doutorado) se exige exame de direito civil aprofundado e comparado: Legislação Civil comparada e Direito Criminal aprofundado e comparado. Para o diploma de estudos superiores de direito público, exame de Direito Constitucional Comparado".

Em 1924 foi criada a Academia Internacional de Direito Comparado, com sede em Haia, no Palácio da Paz, onde funciona também o Tribunal Internacional de Justiça.

Já em 1950, a UNESCO - Organização das Nações Unidas para a Educação, Ciência e Cultura, instituiu um Comitê Internacional de Direito Comparado. Posteriormente, este Comitê foi transformado em um organismo mais amplo, a que se deu o nome da Associação Internacional de Ciências Jurídicas, com sede em Paris. Esta

50 Cf. Guido de Santiago Tawil, "El Estudio Del Derecho Camparado", RDA, 1991, Ano 3, Depalma, Buenos Aires, p. 74.

51 "A mais antiga organização em matéria de direito comparado é a "Société de Legislation Comparée", constituída em França - Paris, em 1869, ainda em plena existência..." (João de Castro Mendes, ob. Citada, p. 107.)

52 Cf. Marc Ancel, "Utilité et Methodes due Droit Comparé Eléments D’Introduction Générale à L'Étude Comparative des Droits", traduzido pelo Prof. Sérgio José Porto, 1980, Sergio Antonio Fabris Editor, Porto Alegre, p. 21.

53 Rafael Bielsa, "Estudios de Derecho Público, I, Derecho Administrativo, 1950, Depalma, Buenos Aires, p. 58. 
Associação tem publicado, em fascículos, uma International Encyclopedia of Comparative Law, que versa sobre direvsos ramos e assuntos do direito comparado, tendo como norma estatutária, "favorecer o conhecimento e a compreensão das nações"; "conhecimento e compreensão: duas nações-chaves do comparativismo moderno ${ }^{54}$.

Destarte, o jurista não pode mais se dar ao luxo de ficar isolado no seu direito nacional, preso a valores e contextos que o mundo pode já ter abolido. Somente na comparação de direitos, através de métodos de estudo concreto, onde a legislação, jurisprudência e história de um povo são confrontadas, poder-se-á atingir o estágio de se tentar evoluir. $O$ direito administrativo já não é mais fruto de idéias isoladas ou esparças, tendo em vista que neste ramo do direito se busca a melhor direção para a Administração Pública e seus Administrados.

É de se registrar que em Estrasburgo existe Faculdade para o ensino do direito comparado e em Luxemburgo funciona o "Instituto Universitário Internacional Luxemburgo".

Também na Europa, em especial em Florença funciona o Instituto Universitário Europeu, onde se destaca o Professor Mauro Cappelletti, sendo ministrado aulas de direito comparado.

Tem-se, portanto, que o direito comparado como método de estudo não pertence apenas ao passado, transmudando-se em verdadeiro instrumento para a edificação permanente do direito administrativo dos povos, não se concebendo a existência de um jurista adstrito apenas ao estudo "das leis do seu país"ss.

\section{Conclusão}

Nos preocupamos em deixar bem evidente a necessidade de comparar-se o direito público das nações, através de pesquisas dos cultores do direito. Não existe nenhuma ciência que permaneça estática, encapsulada em princípios fechados, pois a evolução dos tempos traz consigo a necessidade de uma integração do saber das diferentes nações.

Com a polarização da economia e as atuações em blocos de comércio, os povos desenvolvidos perceberam que se suas fronteiras não ficarem abertas para a evolução,

54 Cf. Marc Ancel, “Utilidade e Método do Direito Comparado", traduzido por Sérgio José Porto, Fabris Editora, Porto Alegre, 1980, p. 118).

55 Cf. Carlos Maximiliano, “Hermenêutica e Aplicação do Direito", 16a Edição, 1996, p. 131. Mais à frente o ínclito jurista arremata: “A vários Códigos e os vários Direitos, especialmente no terreno civil e comercial, constituem faces, aspectos de um só Direito Privado, do moderno Jaus Commune, universal - De uma regiāo para a outra, notam-se pequenas variantes, matrizes perceptíveis; porém, conforme sucede em outros ramos de estudos, não passam de ligeiras alterações de fenômenos constantes na essência e por isso mesmo merecedores de exame para se chegar, com exatidão maior, à regra geral, ao postulado de aplicação uniforme em todo o mundo civilizado. Embora as legislaçōes conservem certa autonomia em parcial originalidade, que correspondem a tradiçöes especiais e aos interesses prevalentes em determinadas regiōes; todavia a aparente diversidade em regular as relaçōes jurídicas apresenta um fundo comum". 
a estagnação dos países será o seu próprio verdugo, quer sob o prisma econômico, quer sob o aspecto cultural.

O direito administrativo comparado, como ramo do direito, assume grande relevância no cenário mundial, decorrendo do fato do mundo não só permitir mais determinados isolamentos, onde a falta de cultura involui o crescimento científico do país, aliado ao fato de que o Estado moderno está voltado para o bem-estar social dos seus súditos, dentro de uma evolução que só com a comparação de direitos é que se atingirá o fim percorrido: A evolução.

Dessa forma, cabe aos responsáveis pela divulgação do direito administrativo do nosso país, incentivar sempre a integração dessa ciência jurídica com a dos países desenvolvidos nessa área, visando sempre o crescimento das relações públicas com os administrados. 